\title{
塔里木河下游河岸带植被的空间结构特征
}

\author{
朱绪超 ${ }^{1,2}$ 袁国富 ${ }^{*}$ 邵明安 ${ }^{1,4}$ 易小波 ${ }^{3}$ 杜 涛 ${ }^{1,2}$ \\ ${ }^{1}$ 中国科学院地理科学与资源研究所生态系统网络观测与模拟重点实验室, 北京 $100101 ;{ }^{2}$ 中国科学院大学, 北京 100049 ; ${ }^{3}$ 西北农林科技大学资源环 \\ 境学院, 陕西杨凌 $712100 ;{ }^{4}$ 西北农林科技大学资源环境学院, 陕西杨凌 712100
}

摘 要 揭示我国内陆河流域下游河岸带植被的空间结构特征, 对于了解我国西北干旱区荒漠河岸带植被的空间分布规律、 指导荒漠化治理和内陆河水资源管理具有重要意义。该研究基于野外大范围植被调查数据支持下的遥感监督分类方法, 利用 Landsat-8 OLI遥感数字图像, 辨识了塔里木河下游柽柳(Tamarix spp.)灌丛、胡杨(Populus euphratica)疏林和芦苇(Phragmites australis)草地3类主要的河岸带植被, 并利用建立的叶面积指数 $(L A I)$ 遥感反演经验模型反演了研究区柽柳灌从和胡杨疏林的 叶面积指数, 旨在从区域尺度和总体趋势上分析荒漠河岸带植被的空间结构和分布特征。结果表明: 在有详细地物资料的基 础上, 遥感监督分类可以作为一种干旱区荒漠河岸带植被分类的有效方法; 遥感分类结果显示塔里木河下游胡杨疏林分布面 积约 $336.4 \mathrm{~km}^{2}$, 柽柳灌从约为 $405.3 \mathrm{~km}^{2}$, 胡杨疏林总体更靠近河道, 柽柳灌丛分布范围更广; 河岸带植被LAI整体很低, 柽柳 灌从和胡杨疏林平均 $L A I$ 值分别为 0.253 和 $0.252, L A I$ 小于 0.5 的植被对应面积分别占柽柳灌丛和胡杨疏林总面积的 $92.4 \%$ 和 90.1\%, 表明了塔里木河下游荒漠河岸植被空间上稀疏分布的特征; 统计结果显示, 河岸带植被结构存在巨大的空间变异性, 其中胡杨疏林比柽柳灌从的空间变异性更大; 河岸带植被 $L A I$ 随距河道距离呈现显著负指数分布规律, 在离河道 $1 \mathrm{~km}$ 范围内 LAI随离河道距离快速下降, 而 $1 \mathrm{~km}$ 外区域叶面积指数普遍低于 0.1 , 表明植被主要分布在河道两侧 $1 \mathrm{~km}$ 范围内。整体稀疏的 空间分布、显著的空间变异性, 以及由LAI体现的植被盖度随距河道距离的负指数下降规律是荒漠河岸带植被空间结构的3个 基本特征。

关键词 极端干旱区, 河岸带植被, 叶面积指数, 空间分布, 监督分类, 塔里木河下游

引用格式: 朱绪超, 袁国富, 邵明安, 易小波, 杜涛 (2015). 塔里木河下游河岸带植被的空间结构特征. 植物生态学报, 39, 1053-1061. doi: 10.17521/cjpe.2015.0102

\section{Spatial pattern of riparian vegetation in desert of the lower Tarim River basin} \begin{abstract}
ZHU Xu-Chao ${ }^{1,2}$, YUAN Guo-Fu ${ }^{1 *}$, SHAO Ming-An ${ }^{1,4}$, YI Xiao-Bo ${ }^{3}$, and DU Tao ${ }^{1,2}$
${ }^{1}$ Key Laboratory of Ecosystem Network Observation and Modeling, Institute of Geographic Sciences and Natural Resources Research, Chinese Academy of Sciences, Beijing 100101, China; ${ }^{2}$ University of Chinese Academy of Sciences, Beijing 100049, China; ${ }^{3}$ State Key Laboratory of Soil Erosion and Dryland Farming on the Loess Plateau, Northwest A \& F University, Yangling, Shaanxi 712100, China; and ${ }^{4}$ College of Resources and Environment, Northwest A \& F University, Yangling, Shaanxi 712100, China
\end{abstract}

\section{Abstract}

Aims Revealing the spatial pattern of riparian vegetation in hyper-arid regions can improve our understanding on the water relations of riparian vegetation in the desert watershed ecosystem, and also can provide valuable scientific guidance for desertification control and water resources management of watershed of the arid region in northwestern China. This research objective is to show the spatial distribution and structures of typical riparian vegetation in hyper-arid desert watershed from regional and overall perspective.

Methods Based on Landsat-8 OLI remote sensing images and a large number of field vegetation surveys, the supervised classification method was used to distinguish three main vegetation categories in the lower Tarim River basin: Tamarix thicket, Populus euphratica woodland, and Phragmites australis grassland. The leaf area index (LAI) of Tamarix thickets and Populus euphratica woodlands were inverted by using the remote-sensed LAI inversion empirical model that we developed.

Important findings Supervised classification supporting abundant information of ground objects by remote sensing was an effective method to determine desert riparian vegetation categories in arid desert regions. The area was $336.4 \mathrm{~km}^{2}$ for the Populus euphratica woodlands and $405.3 \mathrm{~km}^{2}$ for the Tamarix thickets, respectively. The Tamarix thickets had a wider distribution range while the Populus euphratica woodlands grew near the river 
channel. The overall $L A I$ of the riparian vegetation was low. The average $L A I$ value was 0.253 for the Tamarix thickets and 0.252 for the Populus euphratica woodlands. The areas of vegetation with the LAI value of less than 0.5 accounted for $92.4 \%$ and $90.1 \%$ of the total area of the Tamarix thickets and the Populus euphratica woodlands, respectively. The statistic results showed that large spatial variability of the riparian vegetation $L A I$ existed. The spatial variability of the Populus euphratica woodlands was larger than that of the Tamarix thickets. The LAI values of the riparian vegetation had a significant negative exponential relationship with the distances away from the river channel. The $L A I$ values declined rapidly within the distance of $1 \mathrm{~km}$ from the river channel and they were generally lower than 0.1 when the distances beyond $1 \mathrm{~km}$, which indicated that the riparian vegetation was mainly distributed within $1 \mathrm{~km}$ from both side of the river. This research indicated three basic characteristics of the spatial pattern in riparian vegetation from hyper-arid desert regions, including overall sparse spatial distribution, high spatial variability and negative exponential relationship between $L A I$ and distance away from the river channel.

Key words hyper-arid region, riparian vegetations, leaf area index, spatial pattern, supervised classification, lower Tarim River basin

Citation: Zhu XC, Yuan GF, Shao MA, Yi XB, Du T (2015). Spatial pattern of riparian vegetation in desert of the lower Tarim River basin. Chinese Journal of Plant Ecology, 39, 1053-1061. doi: 10.17521/cjpe.2015.0102

荒漠河岸带植被是干旱区一类重要的生态系 统, 对于维系干旱区生态系统稳定、防治沙漠化具 有重要意义。干旱区内陆河流域荒漠河岸带植被的 空间分布及其结构特征通常受制于河道的形态和距 离河道的远近, 反映了水分条件对荒漠河岸带植被 空间结构的控制作用(Zhang et al., 2005; Zhu et al., 2013)。揭示荒漠河岸带植被的空间结构特征及其与 河道的关系能为干旱区内陆河水资源管理和生态恢 复治理提供重要的科学依据。

目前对我国干旱区内陆河沿岸的荒漠河岸带植 被空间分布特征的研究主要是利用遥感和样地调查 两种手段进行的(Zhang et al., 2005; Tao et al., 2008; 朱军涛等, 2011; Zhu et al., 2013; 白元等, 2013)。样 地调查手段很难从整体和大尺度上充分揭示荒漠河 岸带植被的空间分布和结构特征。利用遥感信息能 方便地获取大尺度植被空间信息, 然而目前荒漠植 被遥感反演研究通常较少识别不同植被类型。干旱 区不同植被类型的耗水特征和水分关系差异明显 (Xu et al., 2007; Yuan et al., 2015), 制定有效的干旱 区水资源管理和生态恢复措施需要考虑这种差异。 利用遥感信息提取不同荒漠植被类型的空间分布, 进而从区域尺度揭示这些植被的水分关系, 能为我 们理解荒漠植被水分关系提供新的视角和认识。利 用遥感信息对干旱区植被进行分类的研究已有尝 试, 但是没有从植物水分关系角度和区域尺度上加 以分析。已有的荒漠植被遥感分类研究基于的遥感 影像的分辨率从几十米到几十千米(张旭等, 2005; 古丽·加帕尔等, 2009; 张绘芳等, 2012), 低分辨率
的遥感影像通常不易识别干旱区的植被类型，高分 辨率影像尽管较易判读不同植被类型, 但是在区域 尺度上的应用受到限制。基于特定方法的Landsat 卫星30 $\mathrm{m}$ 空间分辨率的遥感影像能较好地辨识干 旱区不同植被类型，也适合在区域尺度应用。

本研究以塔里木河下游荒漠河岸带植被为研究 对象, 基于Landsat 8 OLI遥感影像信息, 在大范围的 地面植被调查数据的支持下, 利用监督分类法提取 塔里木河下游河岸带主要植被类型及其空间分布, 反演两种主要河岸带植被——柽柳(Tamarix spp.)灌 从和胡杨 (Populus euphratica) 疏林的叶面积指数 $(L A I)$ 。旨在通过对塔里木河下游河岸带植被整体空 间结构的分析，提升我们对极端干旱区荒漠河岸带 植被空间分布和结构特征(以叶面积指数为指标)的 认识: (1)评价基于Landsat-8 OLI遥感影像, 利用监督 分类方法对干旱区荒漠河岸带植被进行分类识别的 效果; (2)从区域尺度和整体角度揭示塔里木河下游 主要河岸带植被的空间分布和结构特征; (3)分析并 揭示荒漠河岸带植被空间格局与河流河道的关系。

\section{1 材料和方法}

\section{1 研究区概况}

塔里木河是我国最长的内陆河, 位于新疆塔里 木盆地, 发源于天山、昆仑山、帕米尔高原, 经塔克 拉玛干沙漠东北缘最终流入台特马湖。研究区位于 塔里木河下游段中的大西海子水库到台特马湖间生 态最为脆弱的一段(图1)。该区深居亚欧大陆内部, 距离海洋较远, 属于暖温带大陆性极端干旱气候, 


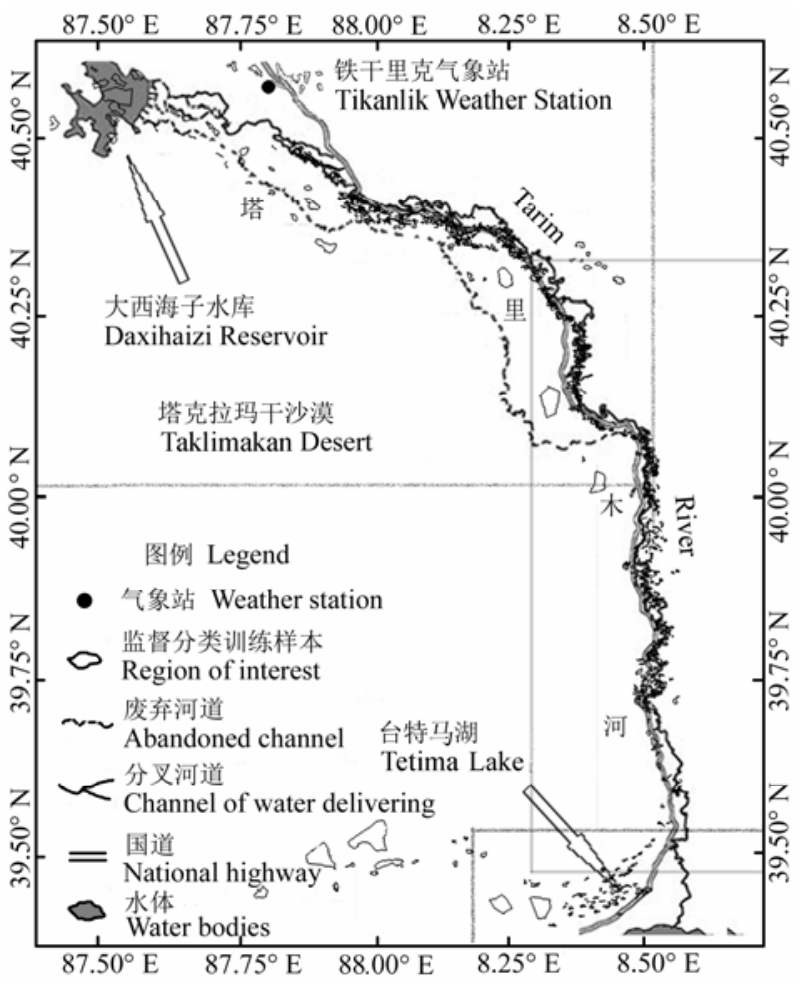

图1 塔里木河下游位置图。虚线框显示本研究采用的三景 遥感影像的范围。

Fig. 1 Location of the lower Tarim River basin. The three dashed line boxes shows the scope of the selected three remote sensing images.

气候干旱, 降水稀少。根据对研究区铁干里克气象 站1957-2012年观测数据的统计, 该区域多年平均 降水量仅为33.7 mm, 降水最少的2001年降水量仅 为 $3.4 \mathrm{~mm}$, 最多的1974年降水量为 $75.7 \mathrm{~mm}$, 一年 中降水主要发生在6、7、8三个月, 占年降水总量的 $67.8 \%$ 。根据气象数据计算, 研究区年潜在蒸散量 $\left(E T_{0}\right)$ 通常是年降水量的25倍以上, 属于极端干旱 区。塔里木河下游地区属于暖温带灌木、半灌木荒 漠地带, 植被类型单一, 受水分条件制约, 基本沿 塔里木河河道分布(张绘芳等, 2007)。主要植被类型 有乔木类胡杨, 灌木类多枝柽柳(Tamarix ramosissima)、刚毛柽柳(T. hispida)、铃铛刺(Halimodendron halodendron)等, 半灌木植物骆驼刺(Alhagi sparsifolia)、罗布麻(Apocynum venetum), 草本植物芦苇 (Phragmites australis)、胀果甘草(Glycyrrhiza inflate) 等, 其中草本植物主要分布在河道两侧, 面积较小 (古丽- 加帕尔等, 2009), 胡杨和柽柳是建群种, 在数 量和空间分布上占有绝对优势(张绘芳等, 2007; Yuan et al., 2014)。由于柽柳和胡杨不同的生长特性,
基本呈现出各自聚集连片分布的特点, 柽柳和胡杨 混合生长的状况很少(古丽·加帕尔等, 2009; 张绘芳 等, 2012)。

\section{2 遥感影像和预处理}

遥感数据选用从美国地质勘探局(United States Geological Survey, USGS)官方网站下载的Landsat-8 OLI遥感影像。Landsat-8卫星于2013年2月发射升空, 与Landsat-7相比, 在波段数量、光谱范围和辐射分 辨率上均进行了改进(徐涵秋和唐菲, 2013)。由于研 究区范围较大, 需用三景影像进行拼接展示。荒漠 河岸带植被在6-8月为生长盛期, 叶面积指数在此 时期变化不大, 为最大化展现植被信息, 选取的遥 感影像时间需要在这一时期内。我们选取条带号和 成像时间分别为142和32的主图像(2013年7月20日), 条带号和成像时间分别为141和32的辅图像(2013年 6月 11 日)和条带号和成像时间分别为 141 和 33 的辅 图像(2013年6月11日), 对3幅影像进行分析处理。影 像空间分辨率为 $30 \mathrm{~m}$, 云量覆盖度低, 总体质量 较好。

下载的Landsat-8 OLI遥感影像为level 1 图像, 在对图像进行分析处理之前, 需要对图像进行预处 理, 主要是辐射校正和几何校正。辐射校正主要包 括辐射定标、大气校正和表观反射率的计算。大气 校正是使用暗目标像元法, 通过在遥感图像上识别 一个“黑物体(dark object)”来计算大气程辐射值, 再 用每个像元值减去大气程辐射值(赵英时, 2003)。几 何校正是选取17个大致均匀分布的野外实测GPS控 制点对遥感影像进行位置纠正, 校正误差为 0.44 个 像元。Landsat-8 OLI遥感影像波段反射率的计算不 同于传统的TM遥感影像, 本文按照USGS官方操作 文档进行计算。遥感图像预处理工作是图像分析和 处理的前提, 决定着地物分类的精度。整个分析和 处理过程使用遥感图像处理软件ENVI 4.6。

\section{3 植被遥感分类方法及精度评价}

采用Landsat-8卫星的5 (近红外)、4 (红)、3 (绿) 三个波段进行解译和分类。监督分类具有操作简单、 计算量小, 可充分利用先验知识等优点, 在遥感地 物分类中获得了广泛的应用。选择监督分类作为研 究区植被分类的主要方法, 其最重要的步骤是选择 训练样本。在本研究中, 我们通过在下游全区域的 大量野外植被调查和定位, 在遥感图像中准确地选 择了1 024个训练样本(图1), 其中317个柽柳灌丛训 
练样本、388个胡杨疏林训练样本、164个沙地训练 样本、14个农田训练样本、66个水体训练样本和 75 个草地训练样本。监督分类过程中选用最大似然法 作为我们进行操作的分类算法。本研究将塔里木河 下游河岸林带地物分为柽柳灌丛、胡杨疏林、芦苇 草地、农田、沙地和水体6类, 能够包含研究区所有 地物类别。利用ENVI 4.6软件对研究区遥感图像进 行逐步处理, 最终可得到研究区植被分类结果。

采用简单随机采样和混淆矩阵两种方法对分类 结果进行精度评价(赵英时, 2003)。简单随机采样法 是随机选择53块野外观测的柽柳灌从和胡杨疏林样 地, 将其经纬度分别输入分类结果图中, 根据准确 率来判断分布最为广泛的柽柳灌从和胡杨疏林的类 别精度。混淆矩阵法是将分类结果与划分的感兴趣 区作为对比来建立混淆矩阵 (刘海江等, 2007), 对分 类结果进行评价。尽管缺少研究区精确的参考分类 图像, 但是在全区域考察记录资料的基础上我们认 为所选择的各类训练区是准确的。根据选取的共 1024 个训练样本建立混淆矩阵, 计算相关指标评 价分类精度。

\section{$1.4 L A I$ 遥感反演}

2013年7月下旬, 在研究区沿着塔里木河下游 河道两岸大致均匀选取了 60块观测样地,包括30块 柽柳灌从样地和30块胡杨疏林样地, 样地大小均为 $50 \mathrm{~m} \times 50 \mathrm{~m}$ 。于早晨、傍晚或阴天使用植物冠层分 析仪LAI-2250 (LI-COR, Lincoln, USA)测量各样地 的叶面积指数, 具体的样地选取原则和 $L A I$ 测量中
的布点方式详见朱绪超等(2014)。研究区以芦苇为 主要建群种的草本植物群落主要分布在河道边以及 湖泊、水库周围, 且分布面积小, 在研究干旱区植物 水分关系方面意义不明显。本研究仅观测了柽柳灌 从和胡杨疏林叶面积指数。利用观测的 $L A I$ 值与遥感 植被指数 $(V I)$ 之间的关系建立适合本研究区特征和 植被特点的 $L A I-V I$ 模型。具体的操作处理详见朱绪 超等(2014)。最后确定的柽柳灌从的最适植被指数 为归一化植被指数 (NDVI), 胡杨疏林的最适植被指 数为大气阻抗植被指数 $(A R V I)$, 对应的 $L A I$ 遥感反 演经验公式(达到显著的相关性, $p<0.01$ ) 分别为:

$L A I_{\mathrm{Tam}}=-0.216(N D V I)^{2}+5.744 N D V I-0.356$

$L A I_{\text {Pop }}=8.119(A R V I)^{2}+2.036 A R V I+0.095$

式中 $L A I_{\mathrm{Tam}}$ 为柽柳的叶面积指数, $L A I_{\mathrm{Pop}}$ 为胡杨的叶 面积指数。利用建立的 $L A I-V I$ 模型, 便可在ENVI 4.6 软件中通过波段运算分别反演出柽柳植被和胡杨植 被LAI的空间分布。

\section{2 结果}

\section{1 植被分类精度评价}

利用简单随机采样法得到的柽柳灌从和胡杨疏 林的类别精度为 $73.6 \%$ 。通过混淆矩阵法得到分类 精度评价表(表1), 可知6类地物类型的总体分类精 度为 $89 \%$, Kappa系数为 0.86 。

从表1中可以看出: 由于沙地、农田和水体在标 准假彩色遥感图像中特征典型, 不论用户精度还是 制图精度，均达到了 $90 \%$ 以上; 草地的分布具有趋

表1 分类类别错分漏分矩阵表

Table 1 Error matrix of wrongly and omissively classified pixels of classification types

\begin{tabular}{|c|c|c|c|c|c|c|c|c|}
\hline $\begin{array}{l}\text { 类别 } \\
\text { Classification }\end{array}$ & $\begin{array}{l}\text { 柽柳灌丛 } \\
\text { Tamarix } \\
\text { thickets }\end{array}$ & $\begin{array}{c}\text { 胡杨疏林 } \\
\text { Populus euphratica } \\
\text { woodlands }\end{array}$ & $\begin{array}{c}\text { 沙地 } \\
\text { Sand lands }\end{array}$ & $\begin{array}{c}\text { 农田 } \\
\text { Farmlands }\end{array}$ & $\begin{array}{c}\text { 水体 } \\
\text { Water bodies }\end{array}$ & $\begin{array}{c}\text { 芦苇草地 } \\
\text { Phragmites } \\
\text { australis grasslands }\end{array}$ & $\begin{array}{l}\text { 总和 } \\
\text { Total }\end{array}$ & $\begin{array}{c}\text { 制图精度(\%) } \\
\text { Mapping accuracy }\end{array}$ \\
\hline 柽柳灌丛 Tamarix thickets & 9982 & 3121 & 1375 & 102 & 48 & 160 & 14788 & 67.5 \\
\hline $\begin{array}{l}\text { 胡杨疏林 } \\
\text { Populus euphratica woodlands }\end{array}$ & 6403 & 23758 & 413 & 30 & 91 & 523 & 31218 & 76.1 \\
\hline 沙地 Sand lands & 1424 & 228 & 38380 & 0 & 21 & 1 & 40054 & 95.8 \\
\hline 农田 Farmlands & 8 & 13 & 0 & 9881 & 1 & 33 & 9936 & 99.4 \\
\hline 水体 Water bodies & 0 & 0 & 0 & 0 & 58371 & 14 & 58385 & 99.9 \\
\hline $\begin{array}{l}\text { 芦苇草地 Phragmites australis } \\
\text { grasslands }\end{array}$ & 569 & 1658 & 23 & 858 & 2110 & 15964 & 21182 & 75.4 \\
\hline 综合 Total & 18386 & 28778 & 40191 & 10871 & 60642 & 16695 & 175563 & - \\
\hline 用户精度 User accuracy (\%) & 54.3 & 82.6 & 95.5 & 90.9 & 96.3 & 95.6 & - & - \\
\hline
\end{tabular}

标题行代表分类后图像上的类别, 左边列代表参考图像上的类别。第一行列出的其他像元数表示参考图像上的柽柳被错误地指定为其他类的像元数 量, 第一列中的其他像元数表示在分类后图像中被错误地指定为柽柳的其他类别的像元数量, 其余行和列的数据依次类推。

The title line is the categories of the classification images and the left column is the categories of the reference images. The other pixel numbers listed in the first row are the numbers of the Tamarix thicket pixels on the reference images incorrectly specified as other categories. The other pixel numbers listed in the first column are the pixel numbers of other categories that were incorrectly specified as Tamarix thicket on the classification image. The data in the remaining rows and columns are the same as mentioned above. 
水性, 有着特定的聚集区域, 便于划分, 因此也具 有较高的用户精度(95.6\%), 草地的制图精度相对较 低, 可能是因为河道两侧的旱地草本长势稀疏，几 乎没有连片的分布, 将其误分为胡杨或者柽柳; 柽 柳灌从和胡杨疏林的分类精度相对偏低, 主要是因 为二者均沿河道分布, 且大多长势稀疏, 盖度值较 低, 有着与土壤类似的光谱特征, 容易发生错分漏 分现象。除了柽柳灌从的用户精度为 $54.3 \%$ 之外, 其 他最低精度也高于 $67 \%$, 总体上, 分类的结果能够 满足研究的需要。分类结果显示: 在具有丰富地物 资料的基础上, 采用简单的监督分类方法具有较高 的识别精度。荒漠河岸林群落结构简单, 植被类型 较少, 这为监督分类方法辨识荒漠植被类型提供了 条件。对于干旱区荒漠河岸林的植被遥感分类来说, 简单的监督分类方法可以获得较满意的分类精度。

\section{2 河岸植被空间分布特征}

监督分类结果显示, 柽柳灌从、胡杨疏林和芦 苇草地三类植被集中分布于河道两侧、大西海子水 库和台特马湖附近(图2)。其中, 柽柳和胡杨主要沿 河道分布, 呈现出胡杨靠近河道、柽柳在胡杨外围 分布的总体格局特征, 这在大西海子水库至阿拉干 一段表现较为明显; 而芦苇草地主要集中于大西海 子水库和台特马湖附近, 在上游段水分较充足的河 段附近也有零星分布。这种分布特征体现了 3 类植被 不同的用水策略, 草类生长需要地表水, 通常在地 表水丰富的地方集中出现; 胡杨耗水量较柽柳大 (Yuan et al., 2015), 一般更靠近河道, 柽柳沿河道与 胡杨交错分布, 但分布范围更广。

利用遥感分类的结果提取了研究区 3 种植被类 型的面积信息(表2)。三类植被的总面积为 1027 $\mathrm{km}^{2}$, 柽柳灌从占地面积最大, 为 $405.3 \mathrm{~km}^{2}$, 胡杨疏 林次之, 为 $336.4 \mathrm{~km}^{2}$, 芦苇草地面积为 $285.3 \mathrm{~km}^{2}$ 。

\section{3 河岸植被叶面积指数的空间分布}

图3显示柽柳灌从和胡杨疏林 $L A I$ 的空间分布, 总体上柽柳和胡杨距离河道越远, $L A I$ 值越小。大西 海子水库至阿拉干一段是生态输水(从大西海子水 库进入塔河河道往下游输送)的首先流经地, 水分 较为充足, 柽柳和胡杨生长较好, $L A I$ 值在0.17-0.50 之间的植被分布相对广泛; 受到河道水面蒸发、土 壤侧渗补给和植物蒸腾的影响, 越往下游, 河道水 分越少, 河岸植被所处地下水位越低, 植被生长越 受到水分条件的限制, 阿拉干至台特马湖一段植被

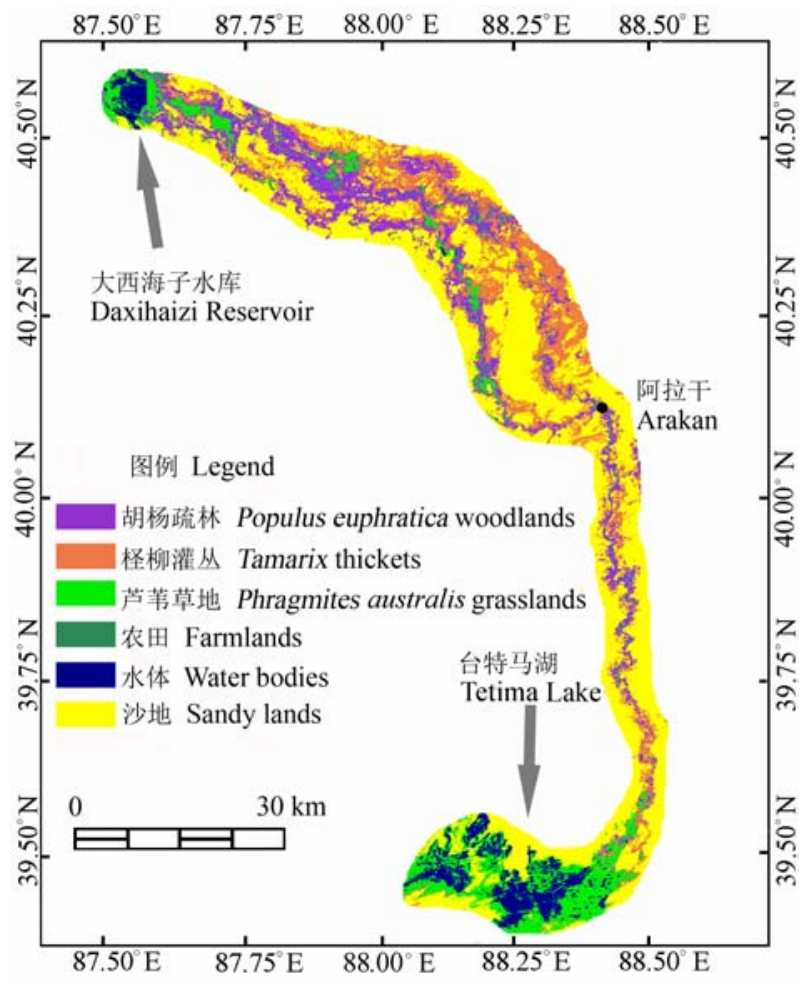

图2 研究区地物分类结果。

Fig. 2 Result of landscape classification in the study area.

表2 研究区遥感解译柽柳灌丛、胡杨疏林、芦苇草地和水体的面积

Table 2 Areas of Tamarix thickets, Populus euphratica woodlands, Phragmites australis grasslands and water bodies in the study area derived by remote sensing interpretation

\begin{tabular}{|c|c|c|}
\hline 类别 Classification & $\begin{array}{c}\text { 像元数 } \\
\text { Number of pixels }\end{array}$ & $\begin{array}{c}\text { 面积 } \\
\text { Area }\left(\mathrm{km}^{2}\right) \\
\end{array}$ \\
\hline 柽柳灌丛 & 450293 & 405.3 \\
\hline Tamarix thickets & & \\
\hline $\begin{array}{l}\text { 胡杨疏林 } \\
\text { Populus euphratica woodlands }\end{array}$ & 373813 & 336.4 \\
\hline $\begin{array}{l}\text { 芦苇草地 } \\
\text { Phragmites australis grasslands }\end{array}$ & 316968 & 285.3 \\
\hline $\begin{array}{l}\text { 水体 } \\
\text { Water bodies }\end{array}$ & 159345 & 143.4 \\
\hline
\end{tabular}

仅限于河道周围很小的范围, $L A I$ 值普遍较低, 多在 0-0.17之间(图3A)。另外从分布上看, 胡杨疏林条带 较为狭窄，更靠近河道分布(图3B), 柽柳灌从条带 稍宽, 呈小片状分布, 在大西海子水库至阿拉干一 段, 柽柳灌丛主要分布在胡杨疏林外围区域, 在靠 近河道的地方也有少量分布, 而在阿拉干至台特马 湖一段基本在胡杨疏林外围区域稀疏分布(图3C)。

对遥感像元中柽柳灌从和胡杨疏林的 $L A I$ 值分 别进行统计, 可得到柽柳灌从和胡杨疏林不同 $L A I$ 值在空间上的面积占比(图4)。分析发现, 柽柳灌丛 和胡杨疏林的 $L A I$ 值大部分小于 0.5 , 分别占了各自 总面积的 $92.4 \%$ 和 $90.1 \%$ 。柽柳灌从分布面积最广的 
$87.50^{\circ} \mathrm{E} 87.75^{\circ} \mathrm{E} 88.00^{\circ} \mathrm{E} 88.25^{\circ} \mathrm{E} 88.50^{\circ} \mathrm{E} 87.50^{\circ} \mathrm{E} 87.75^{\circ} \mathrm{E} 88.00^{\circ} \mathrm{E} 88.25^{\circ} \mathrm{E} 88.50^{\circ} \mathrm{E} 87.50^{\circ} \mathrm{E} 87.75^{\circ} \mathrm{E} 88.00^{\circ} \mathrm{E} 88.25^{\circ} \mathrm{E} 88.50^{\circ} \mathrm{E}$

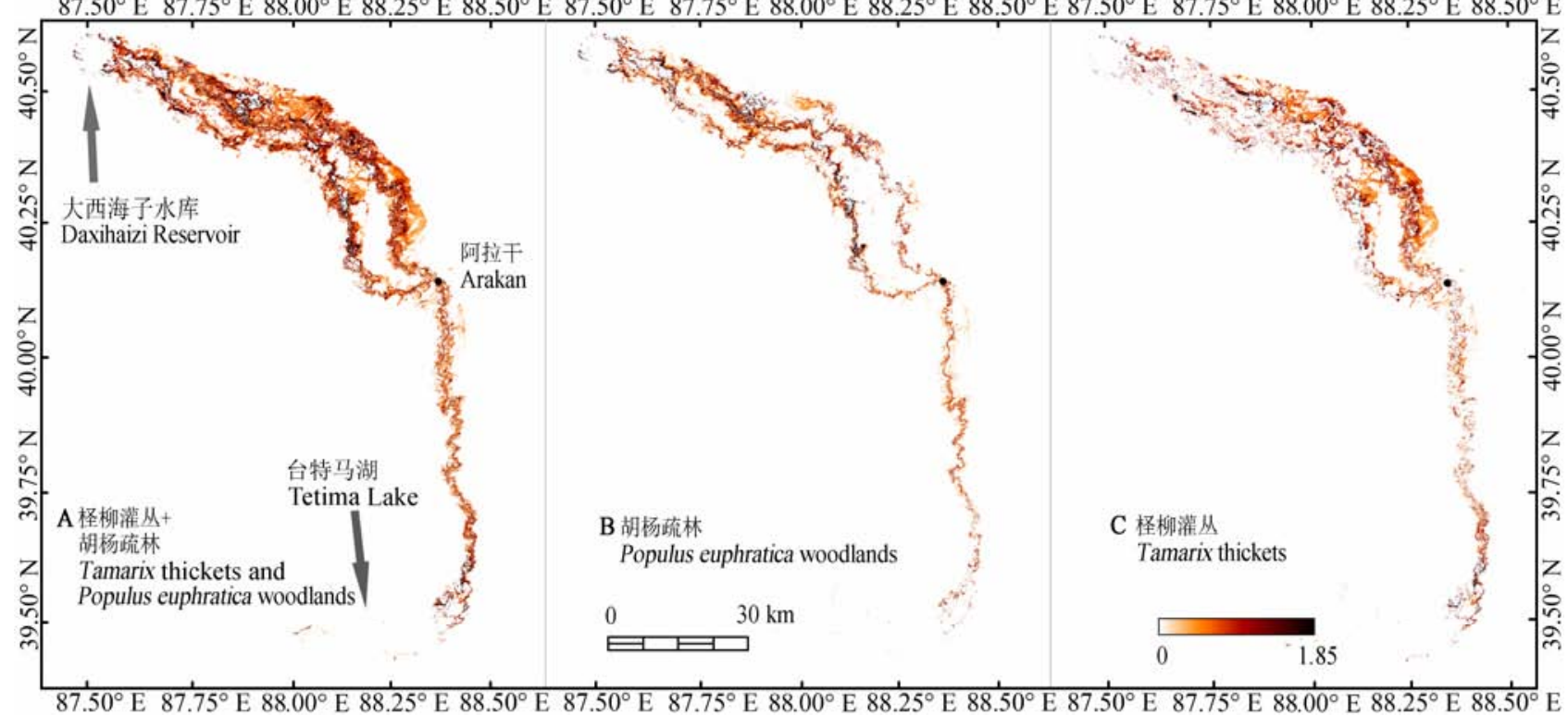

图3 塔里木河下游河岸带胡杨疏林和柽柳灌从叶面积指数空间分布图。

Fig. 3 Spatial distribution of leaf area indices of the Populus euphratica woodlands and the Tamarix thickets in the lower Tarim River basin.

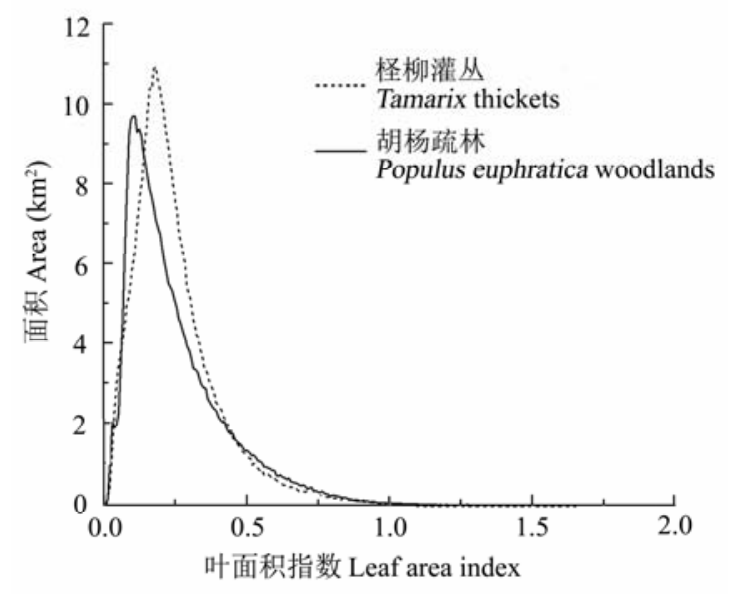

图4 研究区柽柳灌丛和胡杨疏林不同叶面积指数的空间面 积占比。

Fig. 4 Areas of different leaf area indices of Tamarix thickets and Populus euphratica woodlands in the study area.

$L A I$ 值为 0.18 , 对应的面积为 $11.0 \mathrm{~km}^{2}$, 胡杨疏林分 布面积最广的 $L A I$ 值为 0.10 , 对应的面积为 $9.8 \mathrm{~km}^{2}$ (图4)。塔里木河下游地区柽柳灌从和胡杨疏林的 $L A I$ 值均较小, 柽柳 $L A I$ 的最大值为 1.653 , 胡杨为 1.849, 比柽柳 $L A I$ 值稍大(表3)。通过统计特征值可 以看出塔里木河下游荒漠河岸带植被冠层稀疏生长 的特征和显著的空间变异性(表3)。从表3中还可以 看出：柽柳灌从和胡杨疏林 $L A I$ 的均值较为接近,
柽柳灌从 $L A I$ 的均值为 0.253 , 胡杨疏林为 0.252 , 但 胡杨疏林 $L A I$ 的标准差比柽柳灌丛稍大，导致胡杨 疏林的变异系数比柽柳灌从大, 说明胡杨疏林 $L A I$ 值的变化幅度比柽柳疏林大, 表明胡杨疏林结构的 空间变异性更大。整体上看, 塔里木河下游河岸带 植被体现出稀疏生长的冠层特征和巨大的空间变 异性。

\section{4 叶面积指数随垂直于河道距离的变化}

从大西海子水库到台特马湖, 沿河道大致均匀 等距离地选取了 20 个垂直于河道的断面, 分别提取 断面上离河道不同距离的 $L A I$ 值, 将 20 个断面中离 河道相同距离的 $L A I$ 值进行平均, 结果可以表达塔 里木河下游河岸带植被叶面积指数随距河道距离变 化的总体规律(图5)。根据植被LAI数据判读, 塔里木 河下游植被主要分布在距离河道3 $\mathrm{km}$ 之内的范围, 且在距离河道 $1 \mathrm{~km}$ 之外, 植被叶面积指数整体已经 小于 0.1 , 显示河道以外 $1 \mathrm{~km}$ 的区域, 植被已经十分 稀疏。将植被 $L A I$ 与距河道距离数据进行拟合, 得到 拟合方程(图5), $F$ 单因子检验拟合方程显示拟合结 果达到极显著水平 $(p<0.01)$ 。植被 $L A I$ 与距河道的距 离呈显著的负指数关系(决定系数 $R^{2}=0.949$ ), 距离 河道越远, $L A I$ 值越小, 且在河道 $1 \mathrm{~km}$ 范围内 $L A I$ 呈 迅速下降趋势。 
表3 研究区柽柳灌从和胡杨疏林叶面积指数统计特征值

Table 3 Statistical characteristics of leaf area indices of Tamarix thickets and Populus euphratica woodlands

\begin{tabular}{|c|c|c|c|c|c|c|c|}
\hline & $\begin{array}{c}\text { 像元数 } \\
\text { Number of pixels }\end{array}$ & $\begin{array}{c}\text { 最小值 } \\
\text { Minimum }\end{array}$ & $\begin{array}{c}\text { 最大值 } \\
\text { Maximum }\end{array}$ & $\begin{array}{l}\text { 众数 } \\
\text { Mode }\end{array}$ & $\begin{array}{l}\text { 平均值 } \\
\text { Average }\end{array}$ & $\begin{array}{c}\text { 标准偏差 } \\
\text { Standard deviation }\end{array}$ & $\begin{array}{c}\text { 变异系数 } \\
\text { Coefficient of variation (\%) }\end{array}$ \\
\hline 柽柳灌从 Tamarix thickets & 450293 & 0.005 & 1.653 & 0.182 & 0.253 & 0.158 & 62.3 \\
\hline 胡杨疏林 Populus euphratica woodlands & 373813 & 0.007 & 1.849 & 0.102 & 0.252 & 0.178 & 70.5 \\
\hline
\end{tabular}

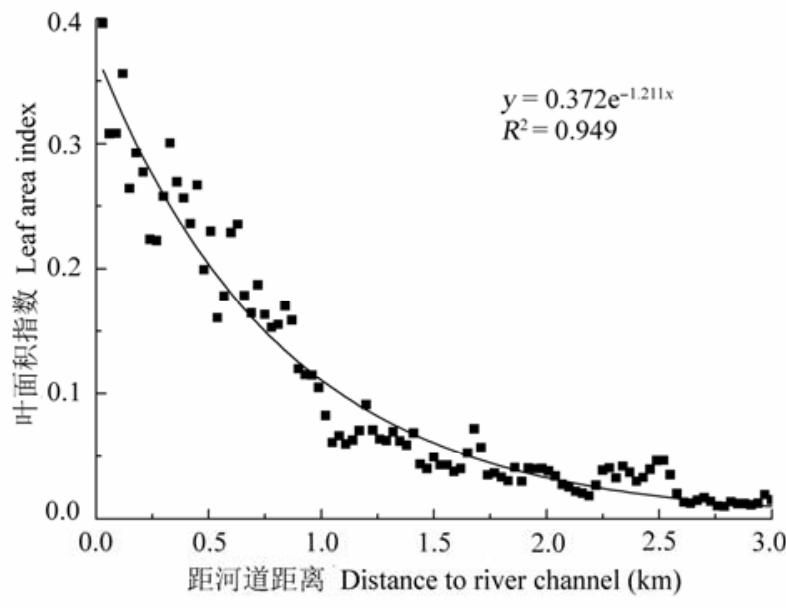

图5 叶面积指数随距河道距离的变化特征。

Fig. 5 Relationship between leaf area indices and distances away from the river channel.

\section{3 讨论}

古丽·加帕尔等(2009)采用Landsat TM遥感影 像, 利用较为复杂的决策树分类、几何光学模型和 光谱角匹配的方法对塔里木河下游地区荒漠河岸林 植被进行识别, 得到的总体分类精度和Kappa系数 均大于 $70 \%$, 而稀疏早地草本的制图精度和灌木类 的用户精度也均不到 $60 \%$, 与本研究的结果较为一 致。多位学者曾利用不同的遥感影像对塔里木河下 游植被进行过分类研究。张旭等(2005) 利用 EOS/MODIS影像监测塔里木河下游植被, 确定从 恰拉水库到台特马湖之间胡杨疏林的面积为 264.6 $\mathrm{km}^{2}$, 柽柳灌从的面积为 $395.3 \mathrm{~km}^{2}$, 比本研究的小, 可能是因将稀疏柽柳灌从和稀疏胡杨林划分为灌木 荒漠类所导致。刘新华等(2013)采用CBERS遥感影 像对研究区进行解译, 结合野外实地调查得到的大 西海子水库至台特马湖之间天然植被面积为 961 $\mathrm{km}^{2}$, 本研究的遥感解译结果与之非常相近。另外, 本研究提取的河岸带植被空间分布特征与邓潮洲 (2010)、张绘芳(2007)等人的实地调查情况也较为一 致。上述研究表明, 基于野外大范围植被调查下的 遥感监督分类方法适用于结构简单、类型单一的荒
漠河岸带植被遥感植被分类中。

从反演的叶面积指数数据可以看出荒漠河岸带 植被空间分布稀疏，反映了干旱气候下荒漠植被空 间结构的固有特点(Okin et al., 2015)。河岸带植被叶 面积指数随距河道的距离呈负指数分布规律，植被 叶面积指数距河道由近到远快速下降，且植被主要 分布在河道两岸 $1 \mathrm{~km}$ 范围内, 这一现象反映了河道 作为荒漠河岸林的主要水源对荒漠河岸林分布和空 间结构的总体控制，体现了极端干旱区生态系统空 间分布和结构特征的特殊控制机制。另一方面，从 $L A I$ 的空间分布看，尽管 $L A I$ 总体呈现出距河道距离 有规律的变化特征, 然而仍然可以看出许多 LAI值 在空间上的斑块状分布特征(图3), 这个结果显示荒 漠河岸带植被结构特征的巨大空间变异性, 不能单 纯地解释为与距河道的远近有关, 其他影响荒漠河 岸带植被空间结构特征的因素, 尤其是河流两岸土 壤属性的空间变异性对河岸带植被空间分布模式的 影响值得进一步研究。

塔里木河是我国最长的内陆河, 在我国西北内 陆河中具有代表性和典型性。塔里木河下游河岸带 植被很少受到人类开垦活动的影响，随着本世纪以 来10余年生态输水工程的持续建设, 下游河岸带植 被逐渐得到恢复(黄粤等, 2013), 因此塔里木河下游 河岸带植被的空间结构特征能够反映西北内陆极端 干旱气候下的荒漠河岸带植被的自然状况, 能够代 表我国西北地区极端干旱的内陆河下游地区的河岸 带植被空间结构特征。对我国内陆河流域沿岸荒漠 河岸带植被空间结构的认识, 有助于我们正确理解 荒漠河岸林的空间分布特征，为合理实施荒漠河岸 林的恢复治理、内陆河水资源的调配与管理提供科 学依据。本文揭示的荒漠河岸带植被空间结构特征 在荒漠河岸带植被恢复和水资源管理方面的意义在 于：(1)在制定植被人工恢复措施中，必须正确理解 荒漠河岸带植被空间分布的稀疏性特征，避免一味 追求植被盖度等违反荒漠河岸带植被自然分布特征 的治理思维; (2)需要正确理解河道孕育荒漠河岸带 
植被的可能空间范围和空间变化特征，制定合理的 生态输水通道。

\section{4 结论}

利用Landsat-8 OLI遥感数字图像, 基于大量野 外植被调查数据支持的训练样本选取, 将塔里木河 下游河岸带相对单一植被下垫面分为柽柳灌从、胡 杨疏林、芦苇草地、农田、水体和沙地共6类，对塔 里木河下游荒漠河岸带植被进行监督分类, 用简单 随机采样法对分类结果进行评价，精度达 $73.6 \%$, 用混淆矩阵进行评价, 分类的总体精度为 $89 \%$, Kappa系数为 0.86 。分类结果与已有研究结果对比也 近似, 表明简单的监督分类方法能够用于干旱区稀 疏荒漠河岸带植被的遥感分类。

塔里木河下游大西海子水库至台特马湖之间胡 杨疏林总面积为 $336.4 \mathrm{~km}^{2}$, 主要分布于河道两侧, 距离河道较近; 柽柳灌丛总面积为 $405.3 \mathrm{~km}^{2}$, 与胡 杨疏林交错分布, 但分布范围更广; 芦苇草地总面 积为 $285.3 \mathrm{~km}^{2}$, 绝大部分分布在大西海子水库和 台特马湖周围, 在阿拉干以上河段两侧也有零星 分布。

研究区柽柳灌从和胡杨疏林的 $L A I$ 值总体上普 遍较低, 统计数据显示塔里木河下游荒漠河岸带植 被总体稀疏分布的结构特征和巨大的空间变异性; 植被叶面积指数随垂直于河道的距离快速下降, 呈 现显著负指数分布规律, 植被主要分布在河道两岸 $1 \mathrm{~km}$ 范围之内, 超过 $1 \mathrm{~km}$ 范围叶面积指数总体低于 0.1 , 植被已经十分稀疏。荒漠河岸林植被的稀疏分 布和空间变异, 以及空间分布受河道控制的特征是 荒漠河岸林空间结构的基本特征，反映了荒漠植物 对干旱气候的适应性以及对河流水源的依赖性。

\section{基金项目 国家自然科学基金(41271050)。}

\section{参考文献}

Bai Y, Xu HL, Tu WX, Ling HB, Fu JY, Wang XY (2013). Population structure and spatial distribution of the Populus euphratica in the mainstream of the Tarim River. Acta Botanica Boreali-Occidentalia Sinica, 33, 1216-1223. (in Chinese with English abstract) [白元, 徐海量, 涂文霞, 凌红波, 傅菍仪, 王希义 (2013). 塔里木河干流胡杨种 群结构与分布格局研究. 西北植物学报, 33, 12161223.]

Deng CZ, Zhang XM, Li L, Wu JX, Zhu JT, Liu GJ, Lü CY (2010). Community characteristics and population struc- ture of Populus euphratica Oliv in lower reaches of Tarim River. Journal of Desert Research, 30, 589-595. (in Chinese with English abstract) [邓潮洲, 张希明, 李利, 吴俊 侠, 朱军涛, 刘国军, 吕朝燕 (2010). 塔里木河下游胡 杨群落特征及种群结构分析. 中国沙漠, 30, 589-595.]

Guli J, Chen X, Ma ZG, Chang C (2009). Classification of sparse desert riparian forest in extreme arid region. Journal of Desert Research, 29, 1153-1161. (in Chinese with English abstract) [古丽·加帕尔, 陈曦, 马忠国, 常存 (2009). 极端干旱区荒漠稀疏河岸林遥感分类研究. 中 国沙漠, 29, 1153-1161.]

Huang Y, Bao AM, Wang SF, Wang YQ, Duan YB (2013). Eco-environmental change in the lower Tarim River under the influence of intermittent water transport. Acta Geographica Sinica, 68, 1251-1262. (in Chinese with English abstract) [黄粤, 包安明, 王士飞, 王永琴, 段远 涁 (2013). 间歇性输水影响下的2001-2011年塔里木河 下游生态环境变化. 地理学报, 68, 1251-1262.]

Liu HJ, Cheng WM, Long E (2007). Landscape changes in a degraded sandy land ecosystem-A case study in the Otindag Sandy Land, Inner Mongolia, China. Journal of Plant Ecology (Chinese Version), 31, 1063-1072. (in Chinese with English abstract) [刘海江, 程维明, 龙恩 (2007). 受损沙地生态系统景观变化分析一以内蒙古 浑善达克沙地为例. 植物生态学报, 31, 1063-1072.]

Liu XH, Xu HL, Ling HB, Bai Y, Fu JY, Zhao XF (2013). Ecological water requirements in the lower reaches of the Tarim River. Journal of Desert Research, 33, 1198-1205. (in Chinese with English abstract) [刘新华, 徐海量, 凌红 波, 白元, 傅荩仪, 赵新风 (2013). 塔里木河下游生态 需水估算. 中国沙漠, 33, 1198-1205.]

Okin GS, de Las Heras MM, Saco PM, Throop HL, Vivoni ER, Parsons AJ, Wainwright J, Peters DPC (2015). Connectivity in dryland landscapes: Shifting concepts of spatial interactions. Frontiers in Ecology and the Environment, 13, 20-27.

Tao H, Gemmer M, Song YD, Jiang T (2008). Ecohydrological responses on water diversion in the lower reaches of the Tarim River, China. Water Resources Research, 44, W08422, doi: 10.1029/2007WR006186.

Xu H, Li Y, Xu GQ, Zou T (2007). Ecophysiological response and morphological adjustment of two Central Asian desert shrubs towards variation in summer precipitation. Plant, Cell \& Environment, 30, 399-409.

Xu HQ, Tang F (2013). Analysis of new characteristics of the first Landsat 8 image and their eco-environmental significance. Acta Ecologica Sinica, 33, 3249-3257. (in Chinese with English abstract) [徐涵秋, 唐菲 (2013). 新一代 Landsat系列卫星: Landsat 8遥感影像新增特征及其生态 环境意义. 生态学报, 33, 3249-3257.]

Yuan GF, Luo Y, Shao MA, Zhang P, Zhu XC (2015). 
Evapotranspiration and its main controlling mechanism over the desert riparian forests in the lower Tarim River Basin. Science China Earth Sciences, 58, 1032-1042.

Yuan GF, Zhang P, Shao MA, Luo Y, Zhu XC (2014). Energy and water exchanges over a riparian Tamarix spp. stand in the lower Tarim River basin under a hyper-arid climate. Agricultural and Forest Meteorology, 194, 144-154.

Zhang HF (2007). The Research on Plant Community Structure and Dominant Species Pattern in the Lower Reaches of Tarim River. Master degree dissertation, Xinjiang Agricultural University, Ürümqi. 52-60. (in Chinese with English abstract). [张绘芳 (2007). 塔里木河下游植物群落 结构特征及优势种群格局研究. 硕士学位论文, 新疆农 业大学, 乌鲁木齐. 52-60.]

Zhang HF, Li X, Gao YQ (2012). Population's pattern analysis based on high-resolution remote sensing images of Quick Bird. Xinjiang Agricultural Sciences, 49, 2029-2034. (in Chinese with English abstract) [张绘芳, 李霞, 高亚琪 (2012). 基于Quick Bird数据的胡杨、柽柳种群格局分析. 新疆农业科学, 49, 2029-2034.]

Zhang HF, Li X, Wang JG, Yang YJ (2007). The structure characteristic of the plant community in the lower reaches of Tarim River. Ecology and Environment, 16, 1219-1224. (in Chinese with English abstract) [张绘芳, 李霞, 王建 刚, 杨艳静 (2007). 塔里木河下游植物群落结构特征分 析. 生态环境, 16, 1219-1224.]

Zhang X, Liu XC, Xiao JD, Yang ZH (2005). Study on the EOS/MODIS image processing and its application in monitoring the vegetation change in the lower reaches of the Tarim River. Arid Zone Research, 22, 532-536. (in Chinese with English abstract) [张旭, 刘新春, 肖继东,
杨志华 (2005). EOS/MODIS影像处理在塔里木河下游 植被监测中的应用. 干旱区研究, 22, 532-536.]

Zhang YM, Chen YN, Pan BR (2005). Distribution and floristics of desert plant communities in the lower reaches of Tarim River, southern Xinjiang, People's Republic of China. Journal of Arid Environments, 63, 772-784.

Zhao YS (2003). Principle and Method of Analysis of Remote Sensing Application. Science Press, Beijing. 204-208. (in Chinese) [赵英时 (2003). 遥感应用分析原理与方法. 科学出版社, 北京. 204-208.]

Zhu JT, Yu JJ, Wang P, Wang ZY (2011). Quantitative classification and analysis of relationships between plant communities and their groundwater environment in the Ejin Desert Oasis of China. Chinese Journal of Plant Ecology, 35, 480-489. (in Chinese with English abstract) [朱军涛, 于静洁, 王平, 王志勇 (2011). 额济纳荒漠绿洲植物群 落的数量分类及其与地下水环境的关系分析. 植物生 态学报, 35, 480-489.]

Zhu JT, Yu JJ, Wang P, Yu Q, Eamus D (2013). Distribution patterns of groundwater-dependent vegetation species diversity and their relationship to groundwater attributes in northwestern China. Ecohydrology, 6, 191-200.

Zhu XC, Yuan GF, Yi XB, Du T (2014). Leaf area index inversion of riparian forest in the lower basin of Tarim River based on Landsat 8 OLI images. Arid Land Geography, 37, 1248-1256. (in Chinese with English abstract) [朱绪 超, 袁国富, 易小波, 杜涛 (2014). 基于Landsat 8 OLI 影像的塔里木河下游河岸林叶面积指数反演. 干旱区 地理, 37, 1248-1256.]

责任编委: 康慕谊 责任编辑: 王 葳 